\title{
Influence of the groundwater level on the bearing capacity of shallow foundations on the rock mass
}

\author{
Ana Alencar ${ }^{1}\left[\right.$ Rubén Galindo $^{1} \cdot$ Svetlana Melentijevic $^{2}$
}

Received: 20 December 2019 / Accepted: 5 July 2021 / Published online: 14 July 2021

(c) The Author(s) 2021

\begin{abstract}
The presence of the groundwater level (GWL) at the rock mass may significantly affect the mechanical behavior, and consequently the bearing capacity. The water particularly modifies two aspects that influence the bearing capacity: the submerged unit weight and the overall geotechnical quality of the rock mass, because water circulation tends to clean and open the joints. This paper is a study of the influence groundwater level has on the ultimate bearing capacity of shallow foundations on the rock mass. The calculations were developed using the finite difference method. The numerical results included three possible locations of groundwater level: at the foundation level, at a depth equal to a quarter of the footing width from the foundation level, and inexistent location. The analysis was based on a sensitivity study with four parameters: foundation width, rock mass type $\left(m_{\mathrm{i}}\right)$, uniaxial compressive strength, and geological strength index. Included in the analysis was the influence of the self-weight of the material on the bearing capacity and the critical depth where the GWL no longer affected the bearing capacity. Finally, a simple approximation of the solution estimated in this study is suggested for practical purposes.
\end{abstract}

Keywords Bearing capacity $\cdot$ Groundwater $\cdot$ Hoek and Brown material $\cdot$ Finite difference method $\cdot$ Self-weight $\cdot$ Strip footing

\section{Introduction}

In rock mechanics, groundwater level (GWL) or the water table is included for the purpose of tunneling (Goodman et al. 1965; Moon and Fernandez 2010; Kong 2011; Farhadian and Katibeh 2017). Bearing capacity solutions in rock masses have been classically based on empirical solutions (Bishoni 1968; Carter and Kulhawy 1988; Goodman 1989; Bowles 1996) and highly influenced by local conditions and the characteristics of the tests. The analytical solution in rock masses, based on the characteristics method (Sokolovskii 1965), was developed by Serrano et al. (2000) for a modified Hoek and Brown failure criterion (Hoek and Brown 1997). But the hypotheses that allow these analytical formulations limit some possible configurations in practice. In particular, the presence of

Ana Alencar

at.santos@alumnos.upm.es

1 ETSI Caminos, C. Y P., Universidad Politécnica de Madrid (UPM), C/Profesor Aranguren s/n, 28040 Madrid, Spain

2 Facultad de Ciencias Geológicas, Universidad Complutense de Madrid (UCM), C/José Antonio Nováis no. 2, 28040 Madrid, Spain a water table close to the foundation level is excluded in the analytical solution and, therefore, unstudied in rock masses. This situation is very frequent in civil engineering and implies a reduction in the bearing capacity of the shallow foundation.

In soil mechanics, the influence of the groundwater level on the bearing capacity is an issue rather than something analyzed. Meyerhof (1955) demonstrated the relevance of the decrease in the effective unit weight of the submerged soil on the bearing capacity and that the variation in groundwater conditions affects the bearing capacity of cohesive soils mainly by changing the cohesion. Analogously, according to Vesic (1973), submerged soil below the footing base reduces the soil strength and may cause the loss of the apparent cohesion because of suction or weak cementation bonds; moreover, the effective unit weight of the submerged soil is about half that of dry soil. Therefore, the bearing capacity load formulas in soils include the change in geomechanical properties induced by the presence of water and the influence of the proximity of the water due to unit weight change. The influence of the GWL was introduced in the classical formulations in soils by reducing the unit weight in the polynomial formulation of bearing 
capacity (Meyerhof 1955; Vesic 1973; Krishnamurthy and Kameswara Rao 1975; Hansen et al 1987; De Simone and Zurlo 1987). It was already known that the GWL affects the bearing capacity if it is located at depth less or equal to the foundation width. Numerical techniques provide intensive analysis enabling Ausilio and Conte (2005) to study groundwater influence on the bearing capacity of shallow foundation in soils by using kinematic approach of limit analysis. The authors observed that the weight term in the polynomial formulation was noticeably reduced with a high value of the instantaneous friction angle.

Reddy and Manjunatha (1997) studied the effect of water table on the ultimate bearing capacity of footings on Toyoura sand possessing anisotropy. They used the characteristics method, obtaining considerable variations in the shape of stability lines with reductions of almost $40 \%$ in the bearing capacity. More recent studies focused on empirical relationships to simulate the bearing capacity of shallow foundations on soils. These were based on the experimental results of footing models resting above the ground water table and model load tests using a hydraulically controlled chamber system (Ajdari and Esmail 2015; Park et al. 2019).

Recent studies focused on seepage, by applying the pseudostatic approach where the pore pressure was included as external forces in the system. Various analyses include the stability of slopes in soils (Veiskarami and Fadaie 2017); rocks (Saada et al. 2012); the bearing capacity of rock (Galindo et al. 2020); soil (Veiskarami and Kumar 2012; Kumar and Chakraborty 2013; Veiskarami and Habibagahi 2013); and joined rock mass (Imani et al. 2012).

In the case of seepage, depending on the direction of the groundwater flow, it can act as a passive (resistant) or active force (Veiskarami and Habibagahi 2013). Thus, the wedge formed below the footing is asymmetric. Veiskarami and Kumar (2012) also show that with an increase in the hydraulic gradient, the nature of the failure patterns becomes more non-symmetrical; for a non-symmetrical failure pattern, there is a higher chance the footing would fail to overturn rather than under simple vertical compression.

In rock masses, Alencar et al. (2019) showed that the instantaneous friction angle under foundation $\left(\rho_{2}\right)$ (Serrano et al. 2000) varies depending on the geological strength index (GSI) value. Implying that when GSI has a low value, the $\rho_{2}$ is greater, because the failure occurs when associated with a low stress status, where the instantaneous friction angle is higher. Emphasizing that low-quality granular soils present a low internal friction angle, however, poor-quality rock mass (related to low GSI values) shows higher instantaneous friction angles. Regarding rock mass, the influence of the GWL location on the bearing capacity is expected to be more significant for high weathered rock mass (lower GSI).

In cases of low GSI, the rock mass can have a bearing capacity that limits completion of the project. And by failing to account for the reduction due to the GWL location, this might overestimate the bearing capacity of the foundation, leading to an unsafe design.

The present authors analyzed a stationary GWL, so that it mainly modified two aspects that affected the bearing capacity: (1) the bulk unit weight and (2) the overall geotechnical quality of the rock mass. The geotechnical quality is usually measured by rock mass classification such as GSI, $Q$-system, and rock mass rating (RMR) that were empirically developed from underground excavation data.

In the RMR classification introduced by Bieniawski (1973, 1989), the presence of water affects $15 \%$ of the rating that define the rock mass quality. In the Q-system proposed by Barton et al. $(1974,1994)$, the score for the state of the rock mass ranges between 0.001 (for exceptionally poor rock) and 1000 (exceptionally good rock); the GWL is one of six factors in the calculation, which may decrease the final rock mass result by 20 times. Hoek et al. (1995, 2002) recommend the GSI classification where the GWL does not influence the result directly, but only the general state of the rock mass is observed. However, the Hoek et al. classification considers that the presence of water erodes the discontinuities.

The effect of GWL on the overall geotechnical quality of the rock mass is already covered in various formulations when estimating the bearing capacity (Carter and Kulhawy 1988; Serrano et al. 2000; Merifield et al. 2006), once the GSI became one of the parameters that is commonly used in the calculation. Merifield et al. (2006) and Clausen (2013) observed that when GSI increases, the bearing capacity becomes less dependent on the unit weight value.

The purpose of the present research is to study the influence of water table depth on the bearing capacity of a shallow foundation on rock, based on geometrical and geotechnical parameters $\left(m_{i}, B\right.$, UCS, and GSI). Based on rock mass geomechanical parameters, a direct formula is given to evaluate the influence of the water table position and then incorporate the result in the analytical formulation. An example for a medium-quality rock mass is included to show the application of the proposed formulation.

\section{Numerical analysis}

The numerical analysis was developed by the finite difference method, using FLAC v.7 (Itasca Consulting Group Inc. 2007). In the finite differences method, every derivative in the set of governing equations is directly replaced by an algebraic expression written in terms of the field variables (stress or displacement) at discrete points in space; these variables are undefined within elements. Using the approach by Wilkins (1964), boundaries can be of any shape, and any element can have any property value. 
FLAC uses an explicit time marching method to solve the algebraic equations. Although a static solution is needed, the dynamic equations of motion are included in the formulation. This approach is used to make the numerical scheme stable because of instability in the physical system model: physical instability can be present with nonlinear materials. In contrast, schemes without inertial terms must use some numerical procedure to treat physical instabilities. This procedure starts with the equations of motion to derive new velocities and displacements from stresses and forces. Then, the strain rates are derived from velocities and new stresses from strain rates.

The numerical implementation of the Hoek-Brown model uses a linear approximation, whereby the nonlinear failure surface is continuously approximated by the Mohr-Coulomb tangent at the current stress level indicated by the minor main stress. The use of tangent linear approximation in geotechnical software is usually considered independent of the numerical method adopted for the calculation. But its use could be the main limitation to obtain adequate numerical solutions when the failure criterion curve is very steep. Thus, in cases of rock masses of low geomechanical quality (low GSI), the Hoek and Brown criteria estimate a very low tensile strength, close to zero. Furthermore, the failure criterion always responds with a steeper slope in the vicinity of the origin for higher values of the parameter $m_{\mathrm{i}}$. This means that in the absence of load (weightless rock mass or without external overload in the boundary adjacent to the foundation), the slopes of the failure criterion are close to $90^{\circ}$ that are very sensitive to stress variations and, therefore, highly unstable. In particular, among the calculation cases that were performed in this research, for values GSI $=10$ and $m_{\mathrm{i}}=32$, sometimes, the unbalanced force was extremely high and the calculation did not converge to valid result.

Using this numerical method, a total of 256 cases of rock masses were analyzed, resulting from the combination of four influential parameters in the ultimate bearing capacity (rock type $\left(m_{\mathrm{i}}\right)$ ), width of the footing $(B)$, uniaxial compressive strength (UCS) of intact rock, and geological strength index (GSI). The values of these parameters are given in Table 1 that covers a wide variety of types and states of rock masses. The values applied for the numerical analysis were limited to a manageable set of cases by selecting parameters within their range of geomechanical variation $\left(m_{\mathrm{i}}, \mathrm{UCS}, \mathrm{GSI}\right)$ and civil engineering widths. A balance

Table 1 Summary of the adopted parameters was performed to have a manageable number of calculation cases and have sufficient results a valid discussion. More relevantly, we wanted to develop an equation that quantifies the effect of water depth on the bearing capacity. Thus, 4 values were considered for each of the parameters, where:

- $m_{\mathrm{i}}$ encompasses extreme values between 5 (Claytones) and 32 (Granite);

- the UCS range of variation with two values above the uniaxial compression strength of the usual construction concrete and another two values below, which may be useful for future soil-structure interaction analysis;

- GSI values should cover a wide range of variation, emphasizing low qualities of rock masses (GSI equal to 10 and 30), since it is not quite common to find a perfectly healthy rock mass.

Numerical calculations were done using 2D models and applied the plane strain condition to represent a strip footing. A symmetrical model was used when only half of the strip footing was represented. The model boundaries were located at a distance that did not interfere with the result.

Three different calculation hypotheses were implemented for all the studied basic cases by adopting the GWL: (1) at the base of the foundation (all rock mass submerged); (2) at a depth equal to a quarter of the footing width $(0.25 \mathrm{~B})$ from the base of the foundation; (3) inexistent (dry rock mass). Figure 1 shows a schematic representation of the variation of the unit weight in the model.

Cases with large values of GSI $(\mathrm{GSI}=85)$ were not calculated under the hypothesis of GWL at $0.25 \mathrm{~B}$ of depth, because it was observed that in cases with higher GSI, the variation between the results with GWL at the foundation

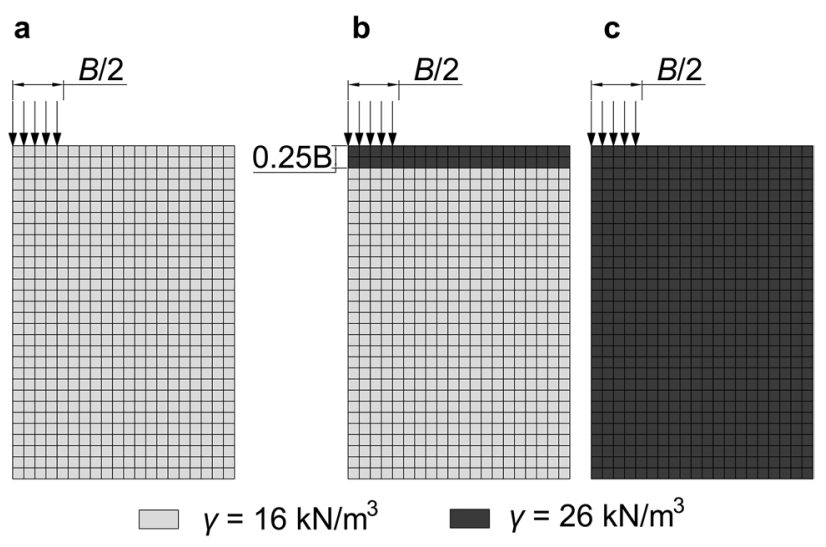

Fig. 1 Representation of the unit weight variation in the model. a Rock mass submerged. b GWL at a depth equal to a quarter of the footing width. $\mathbf{c}$ Dry rock mass 
level and inexistent (dry rock mass) was negligible, less than $7 \%$.

The hypotheses included in all the simulations were the self-weight of the rock mass, the associative flow-rule, and the rough interface at the base of the foundation. In addition, the cases were calculated under the hypothesis of the weightless rock mass to estimate the variation of the bearing capacity due to the consideration of the self-weight of the material.

For numerical calculations, a model is usually simplified by adopting a footing as a load (velocity increments) applied directly on the ground surface. Thus, it is not necessary to define strength parameters for the footing, neither for the interface between the ground and the structure. To simulate a perfectly smooth or rough interface, the nodes where the load is applied are loose or fixed, thus allowing or preventing displacement. In the cases of the present paper, the vertical load was applied by velocity increments, and the nodes where the load was applied were fixed in two perpendicular directions so the interface was perfectly rough.

Numerically, the assumption is that the ultimate bearing capacity is reached when the continuous medium is incapable of supporting more load, because of an internal failure mechanism. In FLAC, the load is applied through velocity increments, and the ultimate bearing capacity is determined from the relation between stresses and displacements of one of the nodes; in the present case, the central node of the foundation was considered.

A convergence study was also performed by analyzing the ultimate bearing capacity values that were obtained under different velocity increments (Fig. 2). The results in Fig. 2 show the dependence of the ultimate bearing capacity relative to the velocity increments applied on the nodes. From Fig. 2, a decrease in the velocity increment values results into a convergence towards a final value by the upper limit in the theoretical method. A convergence study was performed for each case with different combinations of geometrical and geotechnical parameters and summarized in Table 1.

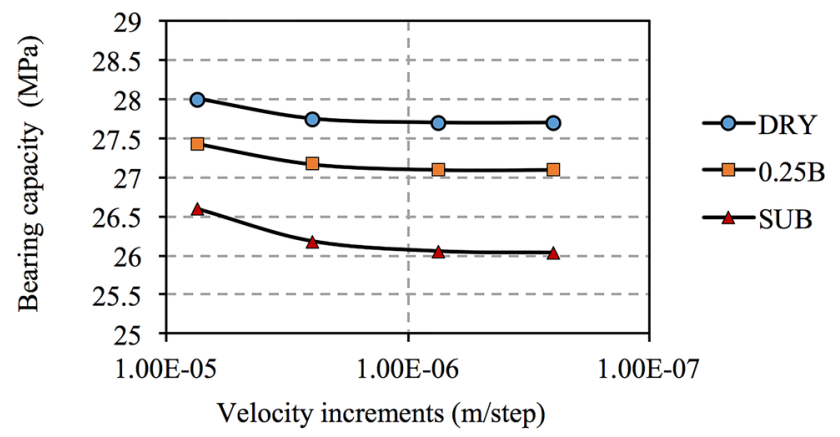

Fig. 2 The bearing capacity versus velocity increment diagram of the central node of the footing. $\left(m_{\mathrm{i}}=20, \mathrm{UCS}=10 \mathrm{MPa}, B=4.5 \mathrm{~m}\right.$ and $\mathrm{GSI}=50$ )

\section{Bearing capacity}

With GWL at the foundation level, we can observe that the unit weight variation can modify the bearing capacity by up to $20 \%$ (see Fig. 3 ). The results were obtained in the extreme condition, comparing a submerged $\left(P_{\mathrm{hSUB}}\right)$ and a dry rock mass $\left(P_{\mathrm{hDRY}}\right)$, with unit weight equal to $16 \mathrm{kN} /$ $\mathrm{m}^{3}$ and $26 \mathrm{kN} / \mathrm{m}^{3}$.

The comparison ratio $\left(\Delta P_{h}^{\mathrm{DRY} / \mathrm{SUB}}\right)$ between the results $P_{\mathrm{hDRY}}$ and $P_{\mathrm{hSUB}}$ is expressed by (1). This formulation $\Delta P_{h}^{X / Y}$ is used for all the graphs of the study that modify the hypothesis " $X$ " and " $Y$ " analyzed in each case.

$\Delta P_{h}^{D R Y / S U B}=\frac{P_{h D R Y}}{P_{h S U B}}-1$

Figure 3 shows the correlation between $P_{\mathrm{hDRY}}$ and $P_{\mathrm{hSUB}}$ as a function of four variable parameters summarized in Table 1. In each graph, a parameter is highlighted: $m_{\mathrm{i}}$ in Fig. 3a; $B$ in Fig. 3b; UCS in Fig. 3c; and GSI in Fig. 3d. If the dispersion ranges of each parameter change in the function of the value (represented in the abscissa axis), it means that the parameter influences the relation between $P_{\mathrm{hDRY}}$ and $P_{\mathrm{hSUB}}$. It should be emphasized that the cases in this study, when $\Delta P_{h}^{\mathrm{DRY} / \mathrm{SUB}}$ is higher than $10 \%$, usually have low GSI (10 or 30); these instances are highlighted in the Fig. 3.

Figure 3 a shows that a slight reduction of the variation between $P_{\mathrm{hDRY}}$ and $P_{\mathrm{hSUB}}$ increases the $m_{\mathrm{i}}$, with maximum dispersion between $15.5 \%\left(m_{\mathrm{i}}=32\right)$ and $21 \%\left(m_{\mathrm{i}}=5\right)$. While in Fig. $3 b$, the trend is to increase the difference between the results with the increment of the footing width, for $B=4.5 \mathrm{~m}$ with a dispersion in the order of 0 to $18 \%$, and with $B=22 \mathrm{~m}$, the range is between 0 and $21 \%$.

Figure $3 \mathrm{c}$ and $\mathrm{d}$ show that the relation between the $P_{\mathrm{hSUB}}$ and $P_{\mathrm{hDRY}}$ depends on the UCS and GSI, with GSI as the most influential parameter when correlating the bearing capacity with different unit weights.

The impact of the variation of the unit weight on the bearing capacity decreases considerably with the increase of the UCS and GSI values. Although with a high GSI $(G S I=85)$, the influence of the location of the GWL on the bearing capacity is less than $7 \%$. A slight influence confirms what Merifield et al. (2006) observed that with the increase of the GSI, the influence of the self-weight of the material in the bearing capacity reduces.

Conducting a joint interpretation of the influence of the UCS and the rock type $\left(m_{\mathrm{i}}\right)$, Fig. 4 shows that the impact of the UCS value on the bearing capacity is greater than the rock type. This is because, for the same rock type, e.g., $m_{\mathrm{i}}=32$, the dispersion range can vary from 2 to $18 \%$ for UCS $=5 \mathrm{MPa}$, and from 0 to $10 \%$ in cases with $\mathrm{UCS}=100 \mathrm{MPa}$. 
Fig. 3 Correlation of $P_{\mathrm{hSUB}}$ and $P_{\mathrm{hDRY}}$ with 4 parameters. a $m_{\mathrm{i}}$. b $B$. c UCS. d GSI
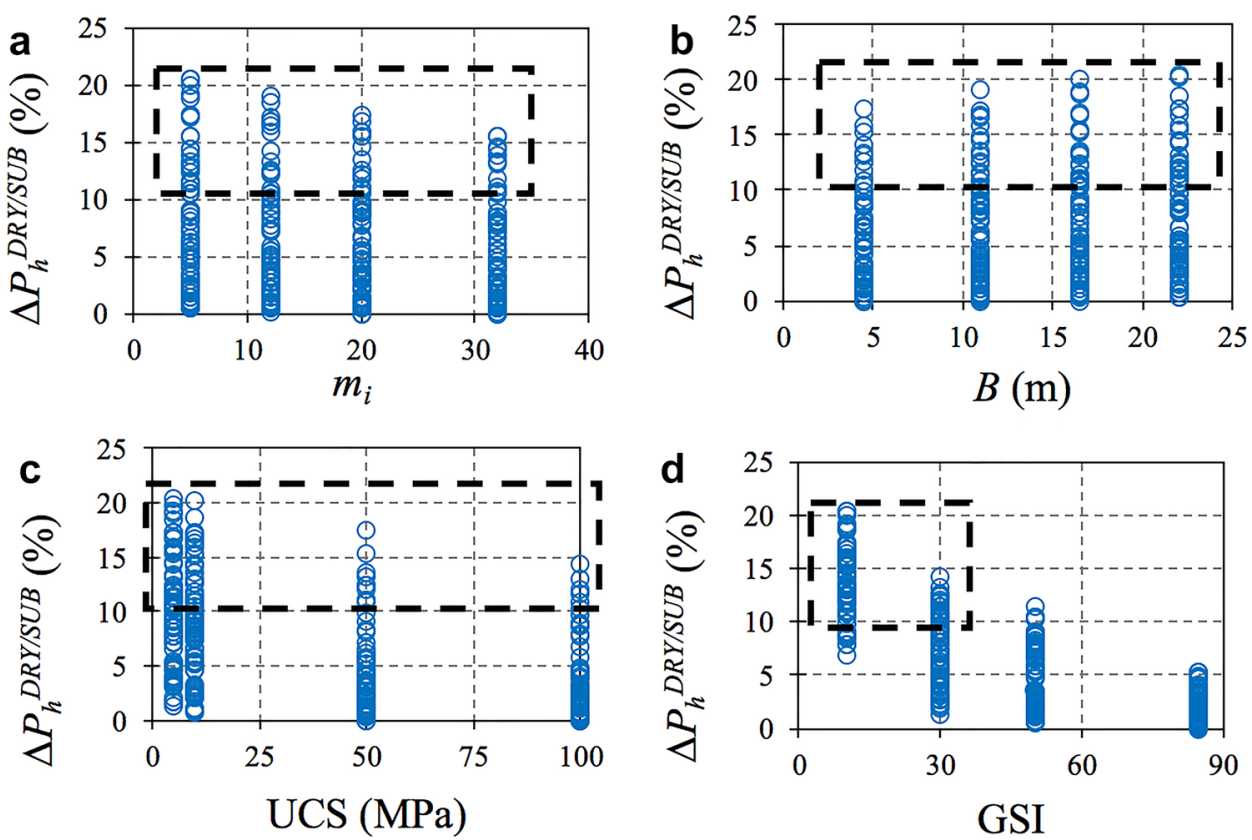

ז
Regarding Fig. 3, the strong influence of the GSI is demonstrated, and from Fig. 4, the influence of the UCS is verified.

\section{GWL at 0.25 B of depth}

To analyze how the variation between $P_{\mathrm{hSUB}}$ and $P_{\mathrm{hDRY}}$ occurs, the bearing capacity was calculated by considering the GWL was located at $0.25 B$ depth $\left(P_{\mathrm{hGWL}}=0.25 B\right)$. The results of $P_{\mathrm{hGWL}}=0.25 \mathrm{~B}$ were then compared under both saturated and dry ground conditions ( $P_{\mathrm{hSUB}}$ and $\left.P_{\mathrm{hDRY}}\right)$.

Given the negligible influence of the unit weight (less than $7 \%$ ) on the bearing capacity for high values of GSI $(\mathrm{GSI}=85)$ under saturated and dry conditions $\left(P_{\mathrm{hSUB}}\right.$ and $P_{\text {hDRY }}$ ) (see Fig. 3 ), the bearing capacity was not calculated for the GWL located at $0.25 B$ depth.

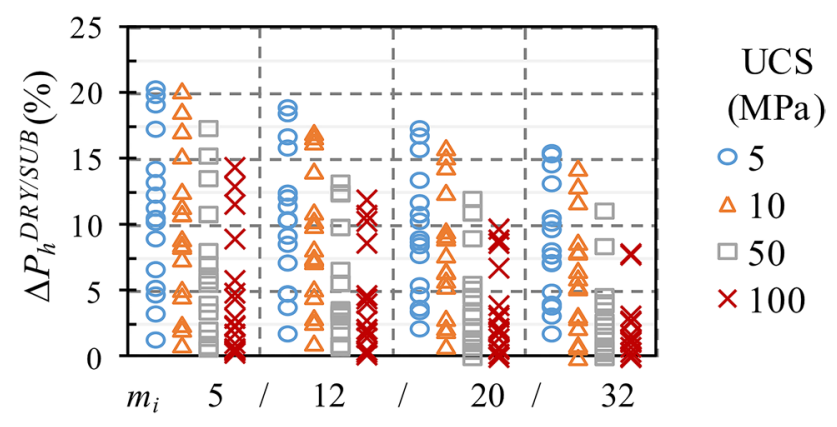

Fig. 4 Correlation between $P_{\mathrm{hSUB}}$ and $P_{\mathrm{hDRY}}$ depending on UCS and $m_{\mathrm{i}}$
Figure 5 shows that the dispersion range is lower than those observed in Fig. 3, as was expected. However, these ranges are high, exceeding $16 \%$, while the maximum influence of the unit weight on the bearing capacity observed is about $21 \%$ (the "Bearing capacity" section). This leads to the conclusion that the bearing capacity is heavily influenced by GWL when it is close to the base level of the foundation. Besides, GSI has a greater influence on the relation between $P_{\mathrm{hGWL}}=0.25 B$ and $P_{\mathrm{hSUB}}$.

Figure 6 shows the variation between the $P_{\mathrm{hGWL}}=0.25 \mathrm{~B}$ and $P_{\mathrm{hDRY}}$ in the function of the GSI, where the range between the results does not exceed $7 \%$. Thus, when the GWL is located at a depth equal or more than to a quarter of the footing width, the bearing capacity is similar to the bearing capacity for the dry rock mass: as in these cases, the influence of the unit weight on the bearing capacity is less than $7 \%$.

\section{Self-weight factor $\left(W_{F}\right)$}

To develop the GWL factor $\left(G_{\mathrm{F}}\right)$, we first analyzed how the self-weight of the material influences the bearing capacity by comparing the results obtained under the extreme conditions of dry $\left(P_{\mathrm{hDRY}}\right)$ and weightless rock mass $\left(P_{\mathrm{hWL}}\right)$.

The parameters of the cases studied under the hypothesis of weightless rock mass are listed in Table 1, but excluding the GSI equal to 30. The influence of the self-weight is not the main topic of the study, and only 192 of the cases analyzed. 
Fig. 5 Correlation of $P_{\mathrm{hSUB}}$ and $P_{\mathrm{hGWL}}=0.25 B$ with 4 parameters. a $m_{\mathrm{i}}$. b $B$. c UCS. d GSI
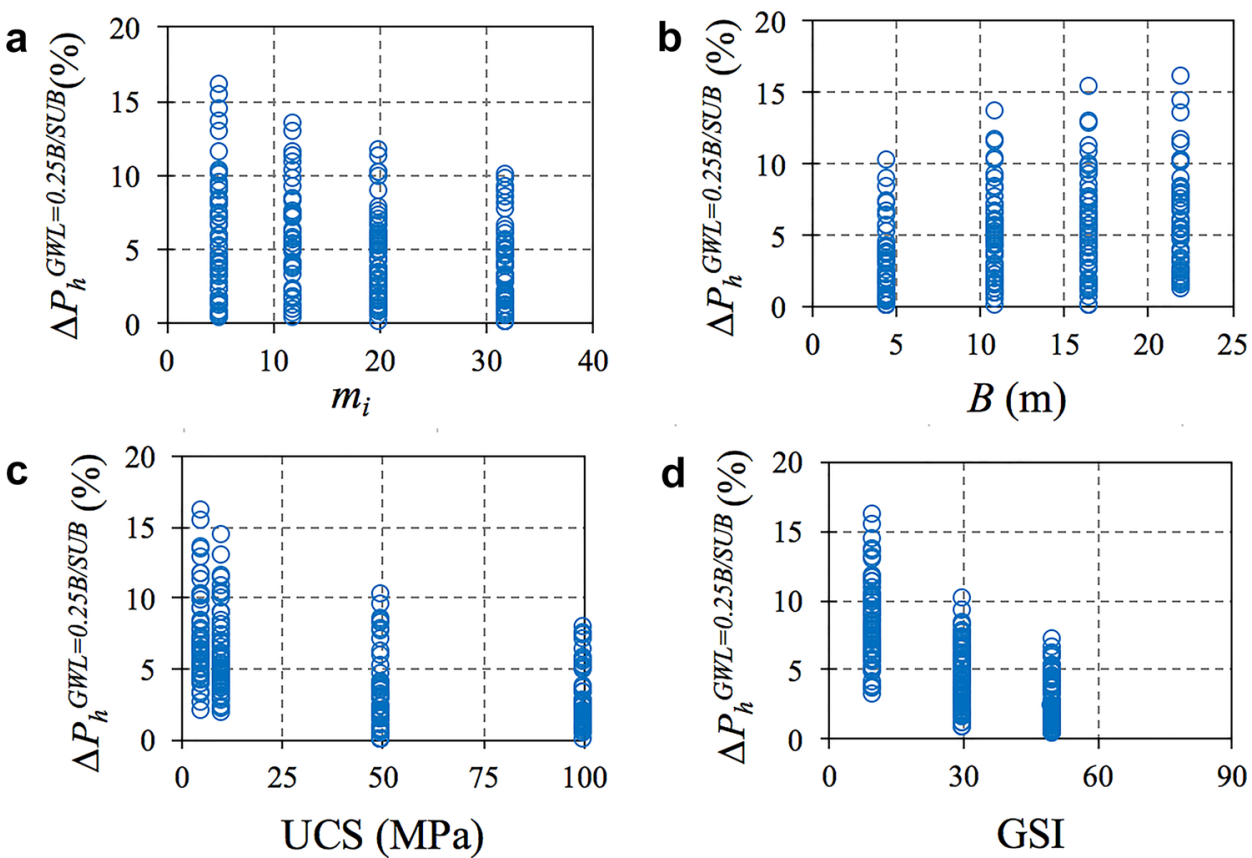

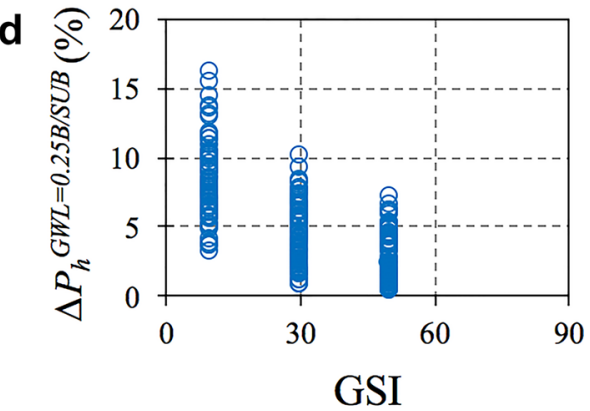

To develop the correction coefficient, we considered the influence of four variable parameters $\left(m_{\mathrm{i}}, B\right.$, UCS, and GSI $)$ in the correlation of the results $\left(P_{\mathrm{hDRY}}\right.$ and $\left.P_{\mathrm{hWL}}\right)$.

The result variations presented in the figures of the following sections do not cover all the cases analyzed. This is because of the numerical instability of the model. It was not possible to obtain results for the combination $m_{\mathrm{i}}=32$ and GSI $=10$ for different values of UCS and $B$ in the hypothesis of the weightless rock mass.

Figure 7 shows that the analyzed four parameters affect the correlation between the results obtained with the hypothesis of the weightless rock mass and considering the self-weight of the material: the influence of the GSI and UCS was the strongest.

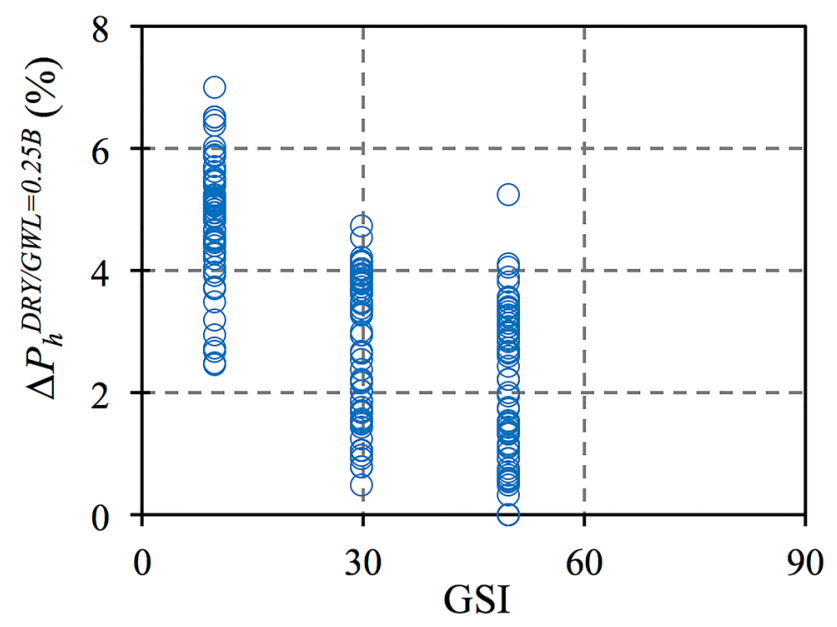

Fig. 6 Correlation of $P_{\mathrm{hDRY}}$ and $P_{\mathrm{hGWL}}=0.25 B$ in function of the GSI
In Fig. 7c and d, a decrease in the dispersion range with the increase of UCS and GSI is observed. It is emphasized that for GSI $=10$, the variation among the results reaches $400 \%$, while for GSI $=50$ the variation is close to $80 \%$, and for greater values of GSI $=85$, the variation is as low as $20 \%$.

Regarding the influence of $m_{\mathrm{i}}$, in Fig. 7a for $m_{\mathrm{i}}=32$, the dispersion range is much lower than for other lower values of $m_{\mathrm{i}}$. This happens because the cases that present dispersions greater than $200 \%$ correspond to a GSI $=10$. As previously mentioned for $m_{\mathrm{i}}=32$ and GSI $=10$, the numerical model does not present convergence; thus, it is not included in Fig. $7 \mathrm{a}$. In general, the tendency is that the higher the value of $m_{\mathrm{i}}$, the smaller the dispersion between results $\left(P_{\mathrm{hDRY}}\right.$ and $\left.P_{\mathrm{hWL}}\right)$.

Figure $7 \mathrm{~b}$ shows the increase in the value of dispersion between results $\left(P_{\mathrm{hSW}}\right.$ and $\left.P_{\mathrm{hWL}}\right)$ with the increase of the value of $B$.

From Fig. 7, it can be concluded that $m_{\mathrm{i}}$ and $B$ affect the dispersion of the results mainly in combination with other parameters, in particular with low values of GSI. In cases where the range between $P_{\mathrm{hDRY}}$ and $P_{\mathrm{hWL}}$ exceeds $60 \%$ that they are associated with GSI $=10$, the dispersion range is very dependent on the values of $m_{\mathrm{i}}$ and $B$.

Regarding UCS, it can be observed in Figs. 7c, and 8 that the dispersion is not linear. There is a greater variation between cases with low UCS (UCS $=5$ and $10 \mathrm{MPa}$ ), than among those with higher UCS of 50 and $100 \mathrm{MPa}$. In other words, as the value of the UCS increases, less dispersion is observed, which occurs exponentially.

The analysis of the results obtained numerically for $P_{\mathrm{hDRY}}$ and $P_{\mathrm{hWL}}$ demonstrates that the correlation of the bearing 
Fig. 7 Correlation of $\mathrm{P}_{\mathrm{hDRY}}$ and $\mathrm{P}_{\mathrm{hWL}}$ with 4 parameters. $\mathbf{a} \mathrm{m}_{\mathrm{i}}, \mathbf{b}$ B, c UCS, d GSI
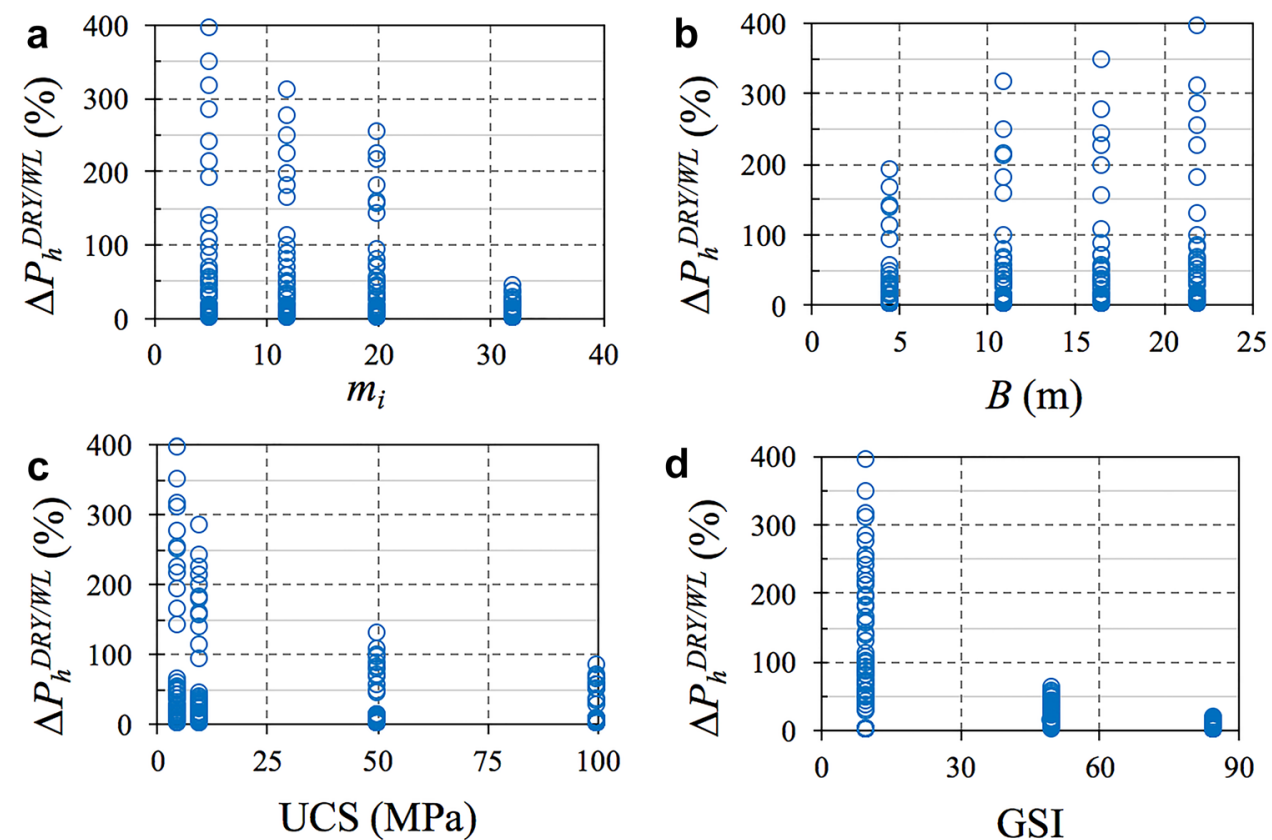

capacity presents a great dispersion depending on the state of the rock mass (GSI), UCS, and to a lesser degree the footing width $(B)$. In addition, the rock type $\left(m_{\mathrm{i}}\right)$ has very little effect on the correlation of results for $P_{\mathrm{hDRY}}$ and $P_{\mathrm{hWL}}$.

In many cases, notably with the combination of high values of GSI and UCS, the increase in load due to the consideration of the self-weight of material is less than $5 \%$ (see Fig. 8). This means that there is no benefit for the user to perform a detailed numerical calculation to estimate the increase in bearing capacity due to the self-weight being too small. For this reason and to allow a better adjustment of $W_{\mathrm{F}}$, the cases in which the load increase by less than $5 \%$ are represented as a graph in Fig. 9.

From Fig. 9 knowing GSI, UCS, and $B$, we can know whether the self-weight of the material increases the bearing capacity by more than $5 \%$. This is because the different $B$ values restrict the differences smaller than $5 \%$ for GSI and UCS. For example, for a footing width of $B=10 \mathrm{~m}$, all combinations of UCS and GSI that are below the line corresponding to $B=10 \mathrm{~m}$ show an increase in the bearing capacity, due to the self-weight of material that exceeds $5 \%$.

If the footing has a width of $B=12 \mathrm{~m}$, a line between $B=10 \mathrm{~m}$ and $B=15 \mathrm{~m}$ should be interpolated. In Fig. 9, the points resulting from the combination of GSI and UCS that are below the line represented the cases with an increment of bearing capacity greater than $5 \%$ due to the consideration of the self-weight.

Once we separated the case studies with an increase lower than $5 \%$, we could develop the correction coefficient due to the self-weight $\left(W_{\mathrm{F}}\right)$. Following the notation used previously, the comparison ratio between the results $P_{\mathrm{hDRY}}$ and $P_{\mathrm{hWL}}$ is expressed by $\Delta P_{h}^{\mathrm{DRY} / \mathrm{WL}}$, which can be considered directly as the self-weight factor $W_{\mathrm{F}}(2)$.

$W_{F}=\Delta P_{h}^{D R Y / W L}=\frac{P_{h D R Y}}{P_{h W L}}-1$
Fig. 8 Correlation between $P_{\mathrm{hWL}}$ and $P_{\mathrm{hDRY}}$ depending on UCS and GSI

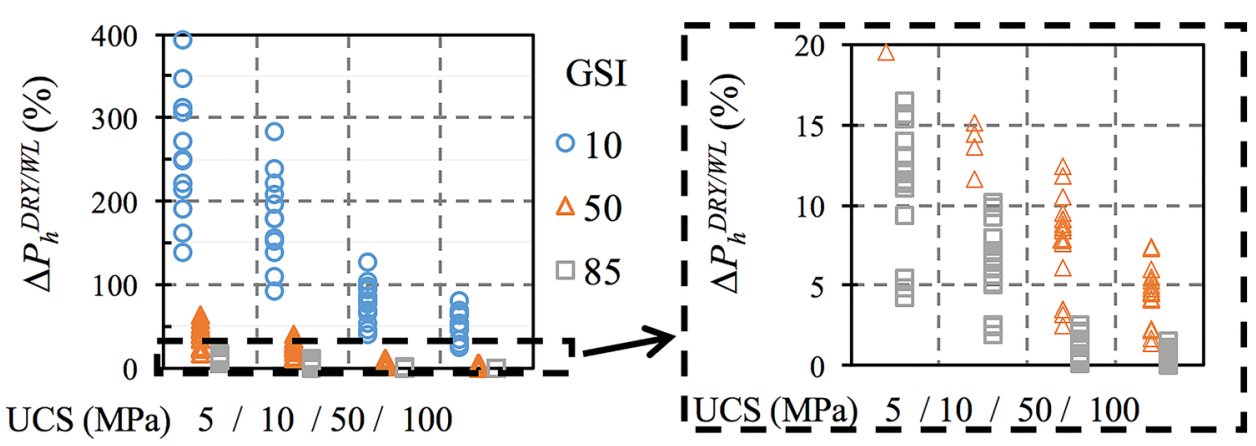




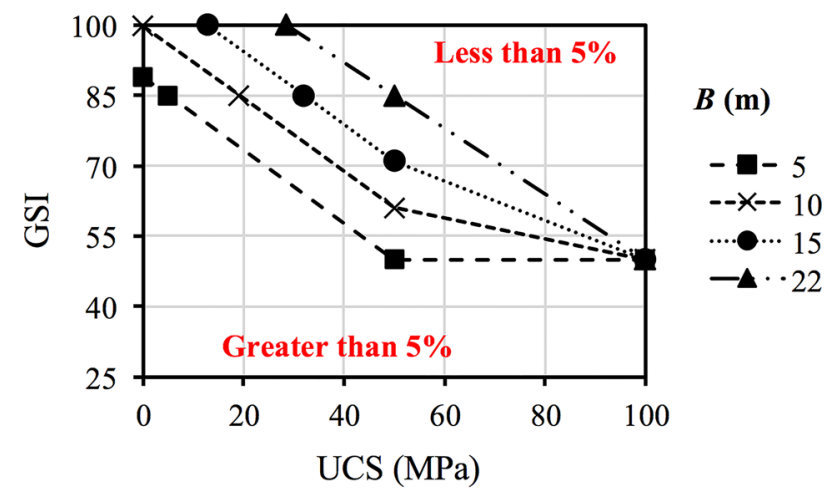

Fig. 9 Limit of $5 \%$ increase in the bearing capacity due to the selfweight of the material

Knowing that the most influential parameters are GSI and UCS, the correlation of the results for each value of the GSI was analyzed according to the UCS (Fig. 10): three equations are given in Table 2. In the graph corresponding to $\mathrm{GSI}=85$ in Fig. 10, there are no equivalent columns for a UCS of 50 and $100 \mathrm{MPa}$. For these combinations of parameters, the variation of the $P_{\mathrm{h}}$ with and without the self-weight of the material is less than 5\%.

From Table 2, for the different GSI values, all the expressions respond to the same structure:

$W_{\mathrm{F}}=\frac{C_{1}}{\mathrm{UCS}^{C_{2}}} \sqrt{\mathrm{B}}$

This equation depends on $C_{1}$ and $C_{2}$, which can be made dependent on the GSI by fitting the three analysis values $(\mathrm{GSI}=10,50,85)$ with simple expressions, for example:

$C_{1}=\frac{3000}{\mathrm{GSI}^{1.2}} ; C_{2}=\frac{165+\mathrm{GSI}}{300}$

To keep the mathematical consistency of (3), it can be normalized by including reference values of the foundation width $\left(B_{\text {ref }}=1 \mathrm{~m}\right)$ and strength $\left(\sigma_{\text {ref }}=1 \mathrm{MPa}\right)$. Therefore, substituting $C_{1}$ and $C_{2}$ in (3) and normalizing it, we obtain (4):

$W_{F}(\%)=\left(\frac{3000}{\mathrm{GSI}^{1.2} \cdot\left(\frac{\mathrm{UCS}}{\sigma_{\mathrm{ref}}}\right)^{\frac{165+\mathrm{GSI}}{300}}}\right) \cdot \sqrt{\frac{B}{B_{\mathrm{ref}}}}$

$\sigma_{\text {ref }}=1 M P a ; B_{\text {ref }}=1 \mathrm{~m}$

\section{GWL factor $\left(G_{F}\right)$}

Once (4) was formulated by accounting for the extreme conditions $\left(W_{\mathrm{F}}\right)$ we developed a factor $\left(G_{\mathrm{F}}\right)$ to consider

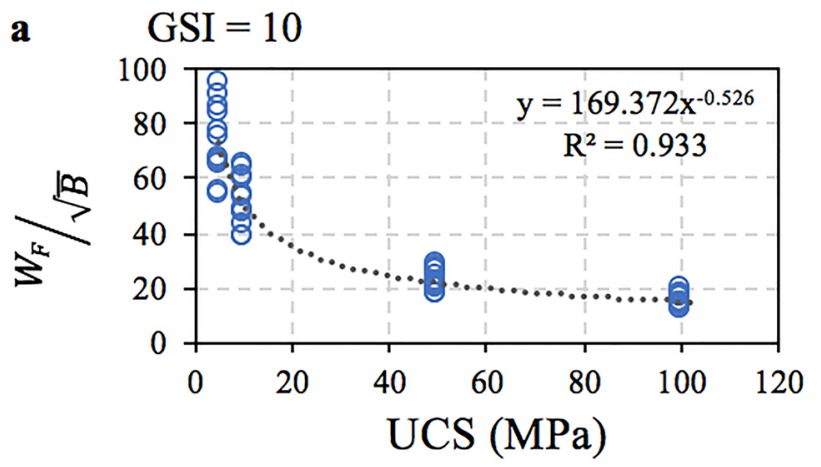

b $\quad \mathrm{GSI}=50$

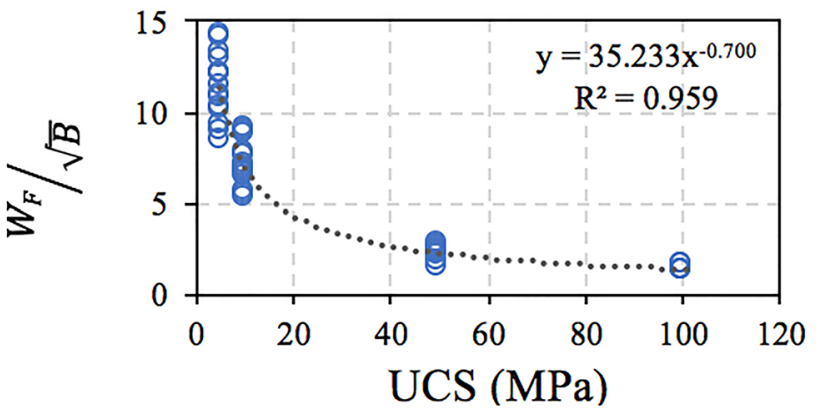

c $\quad \mathrm{GSI}=85$

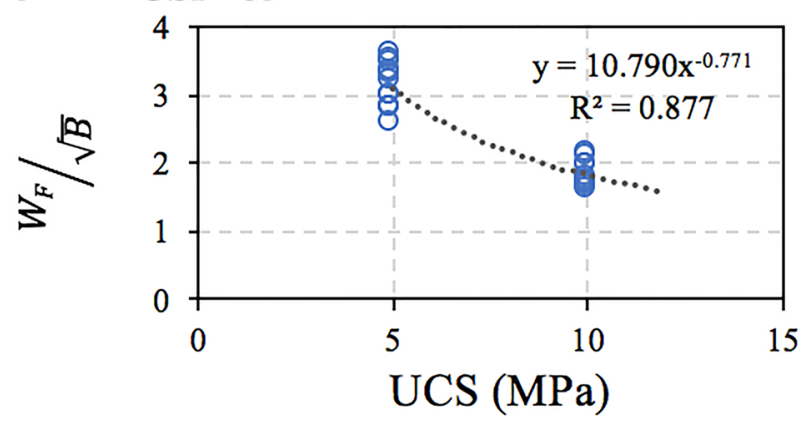

Fig. $10 \mathrm{~W}_{\mathrm{F}}$ equations based on UCS for different values of GSI. a $\mathrm{GSI}=10, \mathbf{b} \mathrm{GSI}=50, \mathbf{c}$ GSI $=85$

the GWL variation in function of the rock weight $(\gamma)$. We adopted the Merifield et al. (2006) relation that applies a factor to the UCS as a function of unit weight value, to adjust the correction coefficient to account for various unit weights at different GWL locations. The resulting equation is as follows:

$G_{F}(\%)=\left(\frac{3000}{G S I^{1.2} \cdot\left(\frac{U C S}{\sigma_{\text {ref }}} \cdot \frac{\gamma_{\text {ref }}}{\gamma_{\text {cal }}}\right)^{\frac{165+G S l}{300}}}\right) \cdot \sqrt{\frac{B}{B_{\text {ref }}}}$

$\sigma_{\text {ref }}=1 \mathrm{MPa} ; B_{\text {ref }}=1 \mathrm{~m} ; \gamma_{\text {ref }}=26 \mathrm{kN} / \mathrm{m}^{3}$

The calculation rock weight $\left(\gamma_{\text {cal }}\right)$ that depends on the GWL location can be estimated with the following 
Table $2 W_{\mathrm{F}}$ equations based on UCS for different values of GSI

\begin{tabular}{ll}
\hline GSI & Equations \\
\hline 10 & $W_{\mathrm{F}}(\%)=169.37 \cdot \mathrm{UCS}^{-0.526} \cdot \sqrt{B}$ \\
50 & $W_{\mathrm{F}}(\%)=35.233 \cdot \mathrm{UCS}^{-0.7} \cdot \sqrt{B}$ \\
85 & $W_{\mathrm{F}}(\%)=10.79 \cdot \mathrm{UCS}^{-0.771} \cdot \sqrt{B}$ \\
\hline
\end{tabular}

equivalence presented in Fig. 11. This was developed based on the numerical results and presented in the "Bearing capacity" and "GWL at $0.25 \mathrm{~B}$ of depth" sections. $\gamma_{\text {SUB }}$ is the submerged rock weight and $\gamma_{\text {ap }}$ is the apparent rock weight at the surface. Therefore, using (5) and Fig. 11, we estimated the percentage increase of the bearing capacity due to the unit weight variation in function of the GWL location.

Depending on the ratio $H / B$ between the depth of the water table under the foundation $(H)$ and the width of the footing $(B)$ from Fig. 11, $\alpha$ and $\gamma_{c a l}$ can be estimated; thus, the value of the $G_{\mathrm{F}}$ factor can also be calculated. So, knowing the bearing capacity of weightless rock mass calculated analytical or numerically, it is possible to estimate the bearing capacity considering different location of the GWL.

\section{$G_{F}$ application}

In this section, an example is given on how to use factor $G_{\mathrm{F}}$ to estimate the bearing capacity. A rock mass with the following geomechanical properties is considered: $m_{\mathrm{i}}=5$, $B=20 \mathrm{~m}, \mathrm{UCS}=30 \mathrm{MPa}, \mathrm{GSI}=40, \gamma_{\mathrm{ap}}=26 \mathrm{kN} / \mathrm{m}^{3}$, and GWL location at a depth equal to a quarter of the footing width $(0.25 B)$ from the base of the foundation.

It is first necessary to estimate the bearing capacity of weightless rock mass $\left(P_{\mathrm{hWL}}\right)$ by a method that can be numerical (FDM, FEM) or analytical (Serrano et al. 2000).

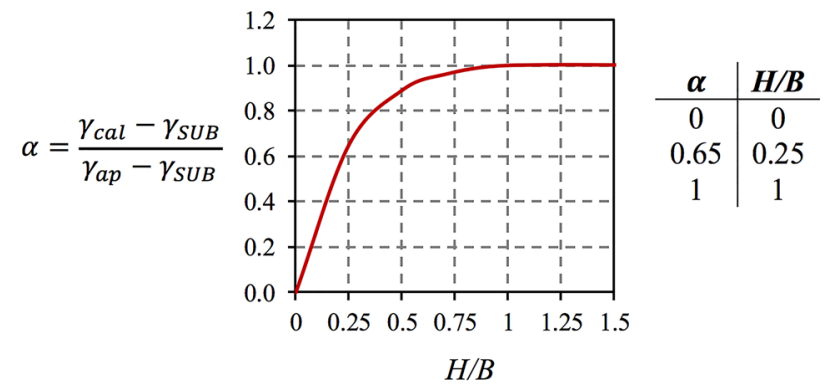

Fig. 11 Correlation of calculation unit weight based on the GWL location
Using the analytical method:

$P_{\mathrm{hWL}}=\beta\left(N_{\beta}-\zeta\right)$

where $N_{\beta}$ is the bearing capacity factor and $\beta$ and $\zeta$ are parameters by Serrano and Olalla (1994). In this example:

$\beta=\frac{m \cdot \mathrm{UCS}}{8}=\frac{m_{\mathrm{i}} e^{\frac{\mathrm{GSI}-100}{28}} \cdot \mathrm{UCS}}{8}=2.2 \mathrm{MPa}$

$\zeta=\frac{8 s}{\mathrm{~m}^{2}}=\frac{8 e^{\frac{\mathrm{GSI}-100}{9}}}{m_{\mathrm{i}} e^{\frac{2(\mathrm{GSI}-100)}{28}}}=0.03$

$N_{\beta}=\frac{\cot ^{2} \rho_{2}}{2}+\frac{1-\sin \rho_{2}}{\sin \rho_{2}}$

where $\rho_{2}$ is the instantaneous friction angle under the foundation that can be calculated from the Riemann invariant:

$I\left(\rho_{2}\right)=I\left(\rho_{1}\right)+\pi / 2$

$I(\rho)=\frac{1}{2}\left[\cot \rho+\ln \cot \frac{\rho}{2}\right]$

In the present case, we can easily obtain the value of the friction angle $\rho_{1}$ in the boundary adjacent to the foundation:

$\rho_{1}=\operatorname{asin} \frac{1}{1+\sqrt{2 \zeta}}=53.4^{\circ}$

$I\left(\rho_{2}\right)=I\left(\rho_{1}=53.4^{\circ}\right)+\frac{\pi}{2}=2.29 \rightarrow \rho_{2}=19.4^{\circ}$

And therefore from (7), $N_{\beta}=6.04$ is obtained, and from (6), the bearing capacity can be calculated:

$P_{\mathrm{hWL}}=\beta\left(N_{\beta}-\zeta\right)=2.2(6.04-0.03)=13.2 \mathrm{MPa}$

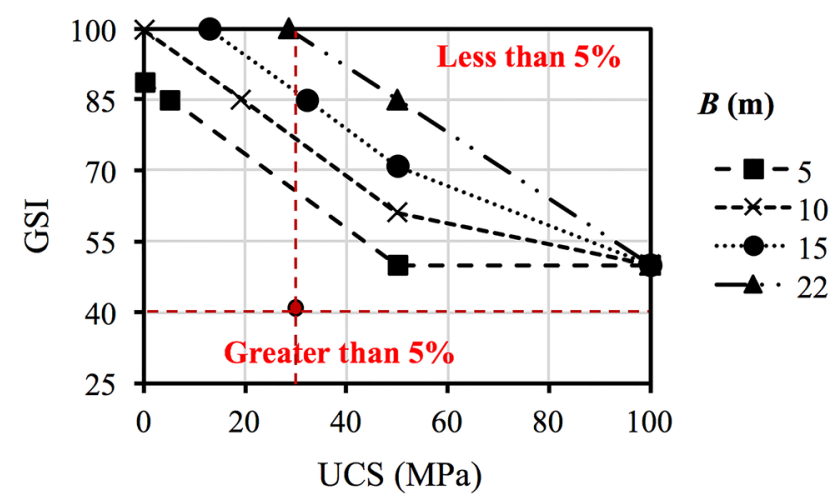

Fig. 12 Influence of the self-weight of the rock mass on the bearing capacity. Application example 
Once $P_{\mathrm{hWL}}$ is known, we recommend looking at Fig. 9 to check whether the self-weight of the rock mass influenced the bearing capacity higher than 5\%. In Fig. 12, the influence is higher than 5\% which is verified.

It is necessary to use the equation presented in Fig. 11 to estimate $\gamma_{\text {cal }}$, in the case $H / B=0.25, \alpha=0.65$, and thus calculate $\gamma_{\mathrm{cal}}$ :

$\alpha=\frac{\gamma_{\mathrm{cal}}-\gamma_{\mathrm{SUB}}}{\gamma_{\mathrm{ap}}-\gamma_{\mathrm{SUB}}} \rightarrow 0.65=\frac{\gamma_{\mathrm{cal}}-16}{26-16} \rightarrow \gamma_{\mathrm{cal}}=22.5 \mathrm{kN} / \mathrm{m}^{3}$

Using (5), factor $G_{\mathrm{F}}$ can be calculated once all parameters are known:

$G_{\mathrm{F}}(\%)=\left(\frac{3000}{40^{1.2} \cdot\left(\frac{30}{1} \cdot \frac{26}{22.5}\right)^{\frac{165+40}{300}}}\right) \cdot \sqrt{\frac{20}{1}}=14.2$

Applying (2):

$\frac{P_{\mathrm{hGWL}=0.25 \mathrm{~B}}}{P_{\mathrm{hWL}}}=1+G_{\mathrm{F}} \rightarrow P_{\mathrm{hGWL}=0.25 \mathrm{~B}}=(1+0.142) \cdot 13.2=15.1 \mathrm{MPa}$

The bearing capacity is estimated using the $G_{\mathrm{F}}$ factor equal to $15.1 \mathrm{MPa}$, which is very similar to the value 15.4 $\mathrm{MPa}$ that can be obtained through a finite difference numerical model using FLAC with GWL at $0.25 B$.

\section{Conclusions}

The stationary GWL mainly modifies two aspects of rock mass that influence the bearing capacity: the bulk unit weight and the overall geotechnical quality of the rock mass. Considering that the geotechnical quality of the rock mass affects the bearing capacity estimation directly in the rock mass classification (GSI), we analyzed the bearing capacity variation in function of the unit weight.

We started this paper by proposing a self-weight factor $\left(W_{\mathrm{F}}\right)$, to estimate the variation of the bearing capacity because of the self-weight of the material. We observed that:

- The parameters with the most impact on the value of the bearing capacity are GSI and UCS: there was an exponential influence when the values of these parameters increased.

- Depending on the combination of the GSI, the UCS, and the footing width $(B)$, the influence of the self-weight of the material may be less than $5 \%$ on the value of the bearing capacity. In cases with high UCS and GSI, the bearing capacity may exceed as much as $400 \%$ for very low values of GSI $(\mathrm{GSI}=10)$ and $\mathrm{UCS}(\mathrm{UCS}=5 \mathrm{MPa})$.
In addition, the GWL factor $\left(G_{\mathrm{F}}\right)$ was developed to incorporate the variable unit weight depending on the GWL location. Therefore, with this parameter, the presence of the GWL can be considered in the estimation of the bearing capacity of the rock mass. Taking into account the comparison described in this research, we can draw the following conclusions:

- The GSI parameter has the most impact on the variation of the bearing capacity between the different hypotheses.

- The unit weight decreases when the water table rises to the foundation level that can reduce the bearing capacity up to $20 \%$, in cases of poor rock mass quality (low GSI, e.g., $\mathrm{GSI}=10$ ).

- In cases with high GSI (e.g., GSI = 85), the variation between the bearing capacity of dry and submerged rock mass is less than $7 \%$.

- In rock mechanics, it was observed that GWL had a greater influence in cases where the water table was located close to the base of the foundation: less than 0.25 $B$ of depth. This depth is much lower than in the field of soil mechanics, where the GWL is not a conditional aspect on the bearing capacity when it is located deeper than the footing width (Ausilio and Conte 2005).

Based on the numerical results, the $W_{\mathrm{F}}$ and the $G_{\mathrm{F}}$ coefficients can be used in conjunction with the analytical method (Serrano et al. 2000), to semi-analytically estimate the bearing capacity of rock mass considering the effect of the selfweight and the GWL.

Funding Open Access funding provided thanks to the CRUE-CSIC agreement with Springer Nature. The research described in this paper was financially supported by the José Entrecanales Ibarra Foundation.

Open Access This article is licensed under a Creative Commons Attribution 4.0 International License, which permits use, sharing, adaptation, distribution and reproduction in any medium or format, as long as you give appropriate credit to the original author(s) and the source, provide a link to the Creative Commons licence, and indicate if changes were made. The images or other third party material in this article are included in the article's Creative Commons licence, unless indicated otherwise in a credit line to the material. If material is not included in the article's Creative Commons licence and your intended use is not permitted by statutory regulation or exceeds the permitted use, you will need to obtain permission directly from the copyright holder. To view a copy of this licence, visit http://creativecommons.org/licenses/by/4.0/.

\section{References}

Ajdari M, Esmail AP (2015) Experimental evaluation of the influence of the level of the ground water table on the bearing capacity of circular footings. IJST, Transactions of Civil Engineering 39:497-510

Alencar A, Galindo RA, Melentijevic S (2019) Bearing capacity of foundation on rock mass depending on footing shape and interface roughness. Geomech Eng 18(4):391-406. https://doi.org/10. 12989/gae.2019.18.4.391 
Ausilio E, Conte E (2005) Influence of groundwater on the bearing capacity of shallow foundations. Can Geotech J 42:663-672. https://doi.org/10.1139/t04-084

Barton N, Lien R, Lunde J (1974) Engineering classification of rock masses for the design of rock support. Rock Mech 6(4):189-236

Barton N, Grimstad E (1994) Rock mass conditions dictate choice between NMT and NATM. Tunnels \& Tunnelling International 26(10):39-42

Bieniawski ZT (1973) Engineering classification of jointed rock masses. South African Institute of Civil Engineers 15(12):333-343

Bieniawski ZT (1989) Engineering rock mass classifications. John Wiley \& Sons, New York

Bishoni BL (1968) Bearing Capacity of a Closely Jointed Rock. Ph.D. DissertationInstitute of Technology, Georgia

Bowles JE (1996) Foundation Analysis and Design, 5th edn. McGrawHill Inc., New York

Carter JP, Kulhawy FH (1988) Analysis and design of foundations socketed into rock, report no. EL-5918. Empire State Electric Engineering Research Corporation and Electric Power Research Institute, New York

Clausen J (2013) Bearing Capacity of circular footings on a HoekBrown material. Int J Rock Mech Min Sci 57:34-41. https://doi. org/10.1016/j.ijrmms.2012.08.004

De Simone P, Zurlo R (1987) The effect of groundwater table on the bearing capacity of shallow foundations. In: Proceedings of the 9th European Conference on SMFE, Dublin. vol 2, pp 677-679

Farhadian H, Katibeh H (2017) New empirical model to evaluate groundwater flow into circular tunnel using multiple regression analysis. Int J Min Sci Technol 27(3):415-421. https://doi.org/10. 1016/j.jimst.2017.03.005

Galindo R, Alencar A, Işık N, Olalla C (2020) Assessment of the bearing capacity of footings on rock masses subjected to seismic and seepage loads. Sustainability 12:10063.https://doi.org/10.3390/ su122310063

Goodman R, Moye D, Schalkwyk A, Javendel I (1965) Groundwater inflow during tunnel driving. Eng Geol 1:150-162

Goodman RE (1989) Introduction to Rock Mechanics, 2nd edn. John Wiley \& Sons, New York

Hansen B, Denver H, Petersen K (1987) The influence of groundwater on bearing capacity of footings. In: Proceedings of the 9th European Conference on Soil Mechanics and Foundation Engineering, Dublin, Ireland, August/September 1987, vol 2, pp 685-690

Hoek E, Brown ET (1997) Practical estimates of rock mass strength. International Journal of Rock Mechanics and Mining Sciences 34(8):1165-1186. https://doi.org/10.1016/S1365-1609(97) 80069-X

Hoek E, Carranza-Torres C, Corkum B (2002) Hoek-Brown failure criterion-2002 Edition. In Hammah R, Bawden W, Curran J, Telesnicki M, editors. Proceedings of NARMS-TAC 2002, Mining Innovation and Technology. Toronto - 10 July 2002, pp. 267-73.

Hoek E, Kaiser PK, Bawden WF (1995) Support of underground excavations in hard rock. Balkema, Rotterdam, Netherlands

Imani M, Fahimifar A, Sharifzadeh M (2012) Upper bound solution for the bearing capacity of submerged jointed rock foundations. Rock Mech Rock Eng 45:639-646. https://doi.org/10.1007/ s00603-011-0215-9
Itasca Consulting Group Inc. (2007) FLAC user's manual. Itasca, Minneapolis

Kong WK (2011) Water ingress assessment for rock tunnels: a tool for risk planning. Rock Mech Rock Eng 44(6):755-765. https://doi. org/10.1007/s00603-011-0163-4

Krishnamurthy S, Kameswara Rao NSV (1975) Effect of submergence on bearing capacity. Soils Found 15(3):61-66

Kumar J, Chakraborty D (2013) Bearing capacity of foundations with inclined groundwater seepage. Int J Geomech 13(5):611-624. https://doi.org/10.1061/(asce)gm.1943-5622.0000241

Meyerhof GG (1955) Influence of roughness of base and ground-water conditions on the ultimate bearing capacity of foundations. Geotechnique 5(3):227-242. https://doi.org/10.1680/geot.1955.5.3. 227

Merifield RS, Lyamin AV, Sloan SW (2006) Limit analysis solutions for the bearing capacity of rock masses using the generalised Hoek-Brown criterion. Int J Rock Mech Min Sci 43:920-937

Moon J, Fernandez G (2010) Effect of excavation-induced groundwater level drawdown on tunnel inflow in a jointed rock mass. Eng Geol 110(3):33-42. https://doi.org/10.1016/j.enggeo.2009.09.002

Park D, Kim I, Kim G, Lee J (2019) Effect of groundwater fluctuation on load carrying performance of shallow foundation. Geomechanics and Engineering 18(6):575-584

Reddy AS, Manjunatha K (1997) Influence of water table on bearing capacity of adjacent strip footings on sand exhibiting anisotropy. Soil and Foundations 37(1):53-64

Saada Z, Maghous S, Garnier D (2012) Stability analysis of rock slopes subjected to seepage forces using the modified Hoek-Brown criterion. Int J Rock Mech Min Sci 55:45-54. https://doi.org/10.1016/j. ijrmms.2012.06.010

Serrano A, Olalla C (1994) Ultimate bearing capacity of rock masses. Int J Rock Mech Min Sci Geomech 31:93-106

Serrano A, Olalla C, González J (2000) Ultimate bearing capacity of rock masses based on the modified Hoek-Brown criterion. Int J Rock Mech Min Sci 37:1013-1018

Sokolovskii VV (1965) Statics of soil media. London: Butterworths Science (Translator R. Jones \& A. Schofield)

Veiskarami M, Fadaie S (2017) Stability of supported vertical cuts in granular matters in presence of the seepage flow by a semianalytical approach. Scientia Iranica 24:537-550. https://doi.org/ 10.24200/sci.2017.2416.

Veiskarami M, Habibagahi G (2013) Foundations bearing capacity subjected to seepage by the kinematic approach of the limit analysis. Front Struct Civ Eng 7:446-455. https://doi.org/10.1007/ s11709-013-0227-5

Veiskarami M, Kumar J (2012) Bearing capacity of foundations subjected to groundwater flow. Geomechanics and Geoengineering 7:1-9. https://doi.org/10.1080/17486025.2011.631038

Vesic AS (1973) Analysis of ultimate loads of shallow foundations. Journal of Soil Mechanics and Foundation Division, ASCE 99(SM1):45-73

Wilkins ML (1964) Fundamental methods in hydrodynamics. Methods Comput Phys 3:211-263 